\title{
Unit of Thermal Conductivity
}

National Cancer Institute

\section{Source}

National Cancer Institute. Unit of Thermal Conductivity. NCI Thesaurus. Code C70440.

A unit to measure an ability of a material to conduct heat measured as areic heat flow rate divided by temperature gradient. 